\title{
Study on the Relationship Between the Development of Forest Tourism and the County's Economic Growth and Third Industry
}

\author{
Xiuhua Wei ${ }^{1,2, a}$, Wei $\mathrm{Cao}^{2}$, Jianzhou Yang ${ }^{1}$ \\ ${ }^{1}$ School of Economics, Fujian Agriculture and Forestry University, China \\ ${ }^{2}$ Fuqing Branch of Fujian Normal University, Fuqing, China \\ a113923819@qq.com
}

\begin{abstract}
Keywords: Forest Tourism; County Economy; The Third Industry; Empirical Analysis.
\end{abstract}
\begin{abstract}
This paper adopts the relevant data of five counties with poor economy in Fujian Province. It establishes a variable coefficient panel data model and analyzes the relationship between forest tourism and the county's economic growth and its third industry. The research results show that the tourism industry in Nanping has a positive influence on the regional economic growth and the third industry development. Based on these results, this paper puts forward some policy suggestions to promote the sustainable development of forest tourism.
\end{abstract}

\section{Introduction}

Forest tourism, or forest ecotourism, means various kinds of activities which directly or indirectly use forested landscapes as distinct attractions for tourists. In March 2014, the State Council officially issued Suggestions on Promoting the Further Implementation of Ecological Province Strategy in Fujian and Accelerating the Construction of Ecological Demonstration Areas, which encourage Fujian to further develop forest tourism industry, and accelerate the transformation and upgrading of forestry industry. Nanping area of Fujian Province is an important forest region in the south of China. The forest coverage rate in Nanping is $76.46 \%$, ranking first in the province. With the excellent ecological environment and abundant forest tourism resources, Nanping becomes the key base for ecological-cultural tourism in Fujian. In recent years, Nanping government attaches great importance to the development of ecological tourism. Authorities of various counties have established development strategies for tourism industry. In 2015, the tourism industrial added value of Nanping was 13 billion 750 million yuan, accounting for $10.27 \%$ of GDP. In accordance with the international standard, when the proportion of industrial added value accounted for $5 \%$ of GDP, the industry can be called the pillar industry of the area. Therefore, the eco-tourism industry has become an important pillar industry in Nanping. At the same time, in 2015, the GDP of Nanping accounted for only 5.16\% of the whole province. The per capita GDP here was 51,126 yuan, which was much lower than Fujian average level of 68260 yuan. Five counties of Nanping, namely Shunchang, Pucheng, Songxi, Zhenghe and Guangze, are listed in the project of poverty relief and development in province. The 13th Five-Year Plan of Nanping puts forward to the target of comprehensive poverty reduction in 2020. Green development, together with the harmonious development of economic growth and ecological protection, are key goals in this plan. Meanwhile, the development of forest tourism industry can help to alleviate poverty. Under that situation, the study of the relationship between the development of forest tourism and economic growth, and the development of the third industry, can not only promote the sustainable and healthy development of tourism industry, but also conducive to the adjustment of industrial structure, and the development of county's economy.

The relationship between tourism industry and economic growth is one of the hot issues in tourism economy. Some scholars indicate that, tourism development can significantly promote economic growth. Khan[1], Wagner[2] and West[3] used complex mathematical models, like input-output models, social accounting matrix and general equilibrium models to carry out empirical examinations on the relationship between tourism development and economic growth. Brida[4], Schubert[5], Duo-xun $\mathrm{Ba}[6]$ and other scholars used econometric research methods to study the relationship in Spain, Mauritius, Turkey, Taiwan, Cyprus, Italy, Tunisia, China and other countries through series 
data analysis. Lee[7], Yan-ping Xiang[8] and other researchers introduced the method of panel estimator into the research of the relationship between tourism and economic growth, and drew the conclusions that tourism development could promote economic growth. The research results of other scholars, however, draw different conclusions. Andrew[9], Oh[10] and other scholars used input-output model and econometric model to study the relationship between tourism and economic growth in British, Turkey, South Korea, the United States, as well as other countries and regions. In their researches, empirical test results show that the development of tourism industry do not promote economic growth.

In summary, existing research mainly focus on countries and provinces. Most scholars believe that the development of tourism can promote economic growth. But the inherent differences between regions lead to the differences in the relationship between economic growth and tourism development At the same time, there are not many studies on the relationship between economic growth and third industry and forest tourism industry in counties, especially poor counties in mountainous areas. This article takes five counties in Nanping area, Shunchang, Pucheng, Songxi, Zhenghe, Guangze, as examples, trying to explain the dynamic relationship between the development of third industry and forest tourism, and the development of economic growth in poor counties, and research the correlation between tourism development, economic growth variables and third industrial added value, in order to provide theoretical guidance for policies on tourism industrial development and poverty alleviation in poor counties under the "New Normal" economic status.

\section{Research Objects}

This research chooses five counties, Shunchang, Pucheng, Songxi, Zhenghe and Guangze as objects. Main reasons go as follows (see Table 1). First, all five counties belong to Nanping area and are near with each other. All of them are key poverty-stricken counties in Fujian province. In 2015, the per capita disposable income for urban residents and per capita income of farmers in the five counties were lower than the average level of Nanping, and much lower than the average level of Fujian province. During the period of 13th Five-Year Plan, they need to complete the tasks of comprehensive poverty reduction. Second, the economic scales of five countries are similar. Apart from Pucheng, the total GDP of other four counties were less than 10 billion yuan in 2015. The influence of heteroscedasticity to estimation efficiency of regression coefficients can be reduced in co-integration regression analysis. Third, the proportions of tourism to GDP (T/GDP) in the five counties are relatively large. In 2015, the proportions of tourism revenue to GDP of the five counties were above 5\%. In Pucheng, the number was as high as $17 \%$. But compared with the average level of $27.75 \%$ in Nanping area, there are still large spaces for development. Fourth, the five counties are rich in eco-tourism resources, and have the potential to develop forest eco-tourism. Fifth, the forest coverage rates (FCR) of five counties are more than $73 \%$. The number of Shunchang is as high as $79.75 \%$.

Table 1. Basic Economic Data of Five Counties in Nanping

\begin{tabular}{|c|c|c|c|c|c|c|c|}
\hline Index & $\begin{array}{c}\text { Fujian } \\
\text { Province }\end{array}$ & $\begin{array}{c}\text { Nan } \\
\text {-ping }\end{array}$ & $\begin{array}{c}\text { Shun-c } \\
\text { hang }\end{array}$ & $\begin{array}{c}\text { Pu- } \\
\text { cheng }\end{array}$ & $\begin{array}{c}\text { Guang- } \\
\text { ze }\end{array}$ & Song-xi & $\begin{array}{c}\text { Zheng- } \\
\text { he }\end{array}$ \\
\hline $\begin{array}{c}\text { GDP } \\
\text { (billion yuan) }\end{array}$ & 2597.982 & 133.951 & 9.097 & 11.906 & 7.841 & 4.284 & 5.001 \\
\hline $\begin{array}{c}\text { GDP per capita } \\
\text { (yuan) }\end{array}$ & 68260.17 & 51126.34 & 48467 & 39953 & 58955 & 36305 & 30309 \\
\hline $\begin{array}{c}\text { per capita disposable } \\
\text { income of urban } \\
\text { residents } \\
\text { (yuan) }\end{array}$ & 33275 & 26120 & 23426 & 24324 & 23400 & 23028 & 23223 \\
\hline $\begin{array}{c}\text { Average income of } \\
\text { rural residents (yuan) }\end{array}$ & 13793 & 12264 & 11619 & 11287 & 10557 & 9376 & 9608 \\
\hline T/GDP(\%) & 4.60 & 27.75 & 12 & 17 & 5 & 6.34 & 6 \\
\hline FCR(\%) & 65.95 & 76.46 & 79.75 & 73.1 & 78.2 & 75.7 & 76.6 \\
\hline
\end{tabular}




\section{Quantitative Analysis}

Variable selection and data sources. Counties of Fujian province do not have special data on forest tourism income. Taking into account of the rich forest tourism resources and the tourism income of Nanping area, and based on the availability of data and the objective situation, this paper selects tourism revenue (TRT) as the proxy variable for forest tourism development. Local economic growth and the development of the third industry are chosen as explanatory variables. The data of GDP is used to represent economic growth, while the industrial added value of third industry (SDC) is employed to describe the development of third industry. This study uses data from Statistical Yearbook of Nanping, statistics bulletin on national economic and social development of five counties, and the annual data released by Tourism Bureau of Nanping City. The sampling period is 2007-2015.

In order to ensure the representativeness and comparability of data, original data are processed with following steps. Natural Logarithms (LNRT) of variables TRT, GDP, SDC are used to do the adjustment of time factors. Variable TRTit is defined as the tourism revenue of ith county in the th year, variable GDPit as the gross economy of ith county in the th year, SDCit as the added value of third industry of ith county in the tth year. An econometric software, Eviews8.0, is used to do panel data analysis.

Measurement models and data analysis. Estimation of panel data model. Panel data models are as following:
LNTRT $_{\text {it }}=\alpha_{\mathrm{i}}+\beta_{\mathrm{i}} \mathrm{GDP}_{\mathrm{it}}+\mu_{\mathrm{it}}$
formulate (1)
LNTRT $_{\text {it }}=\alpha_{\mathrm{i}}+\beta_{\mathrm{i}} \mathrm{SDC}_{\mathrm{it}}+\mu_{\mathrm{it}}$
formulate (2)

In these formulates, $i=1,2,3 \ldots 5$ represents the five counties of Nanping, $t=2007,2008 \ldots 2015$ stands for different years, while $\mu$ is a random disturbance term. According to differences of intercept term $\alpha$ and coefficient term $\beta$, panel data models can be divided as mixed effects model (i.e. $\alpha_{\mathrm{i}}=\alpha_{\mathrm{j}}, \beta_{\mathrm{i}}=$ $\beta_{\mathrm{j}}$ ), variable intercept model (i.e. $\alpha_{\mathrm{i}} \neq \alpha_{\mathrm{j}}, \beta_{\mathrm{i}}=\beta_{\mathrm{j}}$ ) and variable coefficient model (i.e. $\alpha_{\mathrm{i}} \neq \alpha_{\mathrm{j}}, \beta_{\mathrm{i}} \neq \beta_{\mathrm{j}}$ ). In order to avoid deviation, and enhance the effectiveness parameter estimation, this paper tests the two hypotheses by means of covariance analysis firstly,

$$
\begin{aligned}
& \mathrm{H} 1: \beta_{1}=\beta_{2}=\beta_{3}=\ldots \ldots=\beta_{5} \\
& \mathrm{H} 2: \alpha_{1}=\alpha_{2}=\alpha_{3}=\ldots \ldots=\alpha_{5} \text { 且 } \beta_{1}=\beta_{2}=\beta_{3}=\ldots \ldots=\beta_{5}
\end{aligned}
$$

$\mathrm{F}$ tests are made for assumptions $\mathrm{H} 1$ and $\mathrm{H} 2$ to construct statistical magnitude $\mathrm{F} 1$ and $\mathrm{F} 2$ respectively,

$$
\begin{aligned}
& F_{1}=\frac{\left(S_{2}-S_{1}\right) /[(N-1) K]}{S_{1} /[N T-N(K+1)]}-F[(N-1) K, N(T-K-1)] \\
& F_{2}=\frac{\left(S_{3}-S_{1}\right) /[(N-1)(K+1)]}{S_{1} /[N T-N(K+1)]}-F[(N-1)(K+1), N T-N(K+1)]
\end{aligned}
$$

formulate (4)

Among them, S1, S2, S3 are residual sums of square for variable coefficient model, variable intercept model and mixed effect model. $\mathrm{N}$ represents the number of individuals, $\mathrm{K}$ is the number of variables, while $\mathrm{T}$ is the number of time periods. First of all, the relationships between forest tourism industry and local economic growth of five poor counties are analyzed. By using EVIEWS8.0, residual sums of squared residual in three cases are calculated respectively in formulate (1), and obtain $\mathrm{S} 1=5.378146, \mathrm{~S} 2=8.504264, \mathrm{~S} 3=16.65389$. Put $\mathrm{S} 1, \mathrm{~S} 2$ and $\mathrm{S} 3$ respectively in formulates (2) and (3), after calculation we find the following results. $\mathrm{F} 2=9.17>2.217$, hypothesis $\mathrm{H} 2$ is rejected, namely the mixed effect model is refused. F1 $=4.3594>2.689$, original hypothesis $\mathrm{H} 1$ is rejected, namely the variable coefficient model is accepted. The results show that, the relationships between eco-tourism development and local economic growth of five counties are significantly different. 
Table 2 Regression Results of Panel Data Models on Relationship Between Forest Tourism and Local Economic Growth in Five Poor Counties of Fujian

\begin{tabular}{|c|c|c|c|c|}
\hline variable & index & $\begin{array}{l}\text { standard } \\
\text { deviation }\end{array}$ & Value of $\mathrm{T}$ & $\begin{array}{l}\text { Probabi } \\
\text {-lity }\end{array}$ \\
\hline $\mathrm{C}$ & -21.04848 & 1.350979 & -15.58017 & 0.0000 \\
\hline LOGGDP_GZ & 2.389657 & 0.293271 & 8.148292 & 0.0000 \\
\hline LOGGDP_PC & 3.480511 & 0.371576 & 9.366883 & 0.0000 \\
\hline LOGGDP_SC & 4.085780 & 0.403554 & 10.12450 & 0.0000 \\
\hline LOGGDP_SX & 3.227940 & 0.380923 & 8.473995 & 0.0000 \\
\hline LOGGDP_ZH & 2.114425 & 0.334498 & 6.321185 & 0.0000 \\
\hline fixed effect & & & & \\
\hline GZ_C & 5.555608 & & & \\
\hline PC_C & -4.072108 & & & \\
\hline SC_C & -9.487682 & & & \\
\hline SX_C & -0.533413 & & & \\
\hline ZH_C & 8.537596 & & & \\
\hline R-squared & 0.934115 & \multicolumn{2}{|c|}{ Mean dependent var } & 4.753240 \\
\hline Adjusted R-squared & 0.917173 & \multicolumn{2}{|c|}{ S.D. dependent var } & 1.362060 \\
\hline S.E. of regression & 0.391997 & \multicolumn{2}{|c|}{ Akaike info criterion } & 1.158003 \\
\hline Sum squared resid & 5.378146 & \multicolumn{2}{|c|}{ Schwarz criterion } & 1.559483 \\
\hline Log likelihood & -16.05506 & \multicolumn{2}{|c|}{ Hannan-Quinn criter. } & 1.307671 \\
\hline F-statistic & 55.13637 & \multicolumn{2}{|c|}{ Durbin-Watson stat } & 1.864868 \\
\hline Prob(F-statistic) & 0.000000 & & & \\
\hline
\end{tabular}

Table 3 Regression Results of Panel Data Models on Relationship Between Forest Tourism and Third Industry Development in Five Poor Counties of Fujian

\begin{tabular}{|c|c|c|c|c|}
\hline \multirow[b]{2}{*}{ variable } & \multicolumn{3}{|c|}{ standard } & \multirow[b]{2}{*}{ Probability } \\
\hline & index & deviation & Value of T & \\
\hline $\mathrm{C}$ & -21.67749 & 1.181004 & -18.35514 & 0.0000 \\
\hline LOGSDC_GZ & 3.468576 & 0.361358 & 9.598721 & 0.0000 \\
\hline LOGSDC_PC & 3.691578 & 0.338091 & 10.91889 & 0.0000 \\
\hline LOGSDC_SC & 4.474261 & 0.377963 & 11.83782 & 0.0000 \\
\hline LOGSDC_SX & 3.862547 & 0.390062 & 9.902404 & 0.0000 \\
\hline LOGSDC_ZH & 2.505593 & 0.336783 & 7.439793 & 0.0000 \\
\hline
\end{tabular}

fixed effects

$\begin{array}{lr}\text { GZ_C } & 1.776336 \\ \text { PC_C } & -1.536993 \\ \text { SC_C } & -8.172645 \\ \text { SX_C } & -0.732309\end{array}$




\begin{tabular}{llll}
\multicolumn{3}{c}{ ZH_C } & \\
\hline \hline R-squared & 0.950772 & Mean dependent var & 4.753240 \\
Adjusted R-squared & 0.938113 & S.D. dependent var & 1.362060 \\
S.E. of regression & 0.338841 & Akaike info criterion & 0.866559 \\
Sum squared resid & 4.018466 & Schwarz criterion & 1.268040 \\
Log likelihood & -9.497585 & Hannan-Quinn criter. & 1.016227 \\
F-statistic & 75.10803 & Durbin-Watson stat & 1.996064 \\
Prob(F-statistic) & 0.000000 & & \\
\hline
\end{tabular}

Empirical analysis results. According to formula(1), the variable coefficient model is established. Parameter estimation is made by using the panel data of 2007 - 2015 . Considering sometimes synchronization cannot represent relationship, and the heteroscedasticity of section exists in residual samples of cross-section data, parameter estimation is conducted to the models of relationship between forest tourism industry and local economic growth and third industry development in five poor counties through cross section weighting least square method. Results of regression analysis can be seen in Table 2 and table 3. From table 2, we find that the regression fit of variable coefficient panel model of the relationship between forest tourism industry and local economic growth is relatively good. The regression fit is $93.41 \%$. From table 3 we know that regression fit of variable coefficient panel model of the relationship between forest tourism industry and third industry development is relatively good. The regression fit is $95.08 \%$. From the coefficients of explanatory variables LOGGDP and LOGSDC, we can find that the $T$ values of variable regression coefficient and $\mathrm{P}$ values of probability pass the significance test of $1 \%$, and the regression coefficients of five counties are positive. The data shows that the development of forest tourism industry in these five impoverished counties can promote local economic growth and the development of the third industry.

From the coefficient values of $\beta_{i}$, we can find the contribution of forest tourism industry to local economic growth and the development of third industry are different, but the contribution is high. Table 2 shows that the coefficients of elasticity of forest tourism industry to economic development of five counties are greater than 2, indicating the development forest tourism can promote local economy development significantly. For example, the coefficient of elasticity in Shunchang county is 4.085780, means that if other factors are constant, every 1 percentage increase of forest tourism can drive 4.085780 percentage increase of gross economy of Shunchang. Table 3 shows that, the coefficients of elasticity of forest tourism industry to third industry development of five counties are greater than 2, and of four counties are greater than 3, indicating the development forest tourism can promote third industry development significantly. For example, the coefficient of elasticity in Shunchang county is 4.474261 , means that if other factors are constant, every 1 percentage increase of forest tourism can drive 4.474261 percentage increase of third industry added value.

From the coefficient values of model $\alpha_{i}$, we can find the rates of deviation on normal output of local economy and third industry to average normal output are not the same, which shows that the forest tourism development has different influences on the growth of county economy and the development of third industry. In the model, $\alpha$ represents the average output of local economy and third industry, $\alpha$ i represents the deviation of normal output of local economy and third industry. From table 2 and table 3, we can find that the fixed effects of tourism industry to regional economic growth in five counties are 5.555608, $-4.072108,-9.487682,-0.533413$ and 8.537596. Five fixed effects of tourism industry development on third industry are $1.776336,-1.536993,-8.172645,-0.732309$ and 8.665612, shows the rates of deviation on normal output of local economy and third industry to average normal output are not the same. The deviation direction of Guangze and Zhenghe is the opposite of other counties. 


\section{Conclusions and Suggestions}

This paper selects data of five counties in poor mountainous areas of Fujian from 2015 to 2007, and adopts variable coefficient panel data models to empirically analyze the relationship between forest tourism industry and economic growth and the development the third industry. The result shows that, the development of forest tourism industry in these counties can promote the development of third industry and local economy. Therefore, in order to reduce the regional disparity of economic growth and third industry, poor counties should attach great importance to forest tourism industry, trying to realize the benign interactions between forest tourism and economic growth and third industry. Specific measures include following aspects.

Insisting on the harmoniously development of tourism industry and ecological protection. With the development of forest tourism industry, we can realize the harmonious unification of social benefits, economic benefits and forest ecological protection. At the same time, the rapid development of forest tourism industry can effectively promote the adjustment of forestry industrial structure, and alleviate the contradiction between protection and development. Forest tourism industry is a sustainable development industry which consume little forest resources. [11] At present, the forest tourism in poor counties develops rapidly, but the extensive management cannot meet the requirements of sustainable development. Therefore, these counties should actively promote the transformation and upgrading of forest tourism industry to achieve optimized industrial structure. Taking into account of products quality, social benefits and forest tourism resources protection, benign interactions between forest tourism development and economic growth can be achieved.

Extending industry chain of forest tourism. Tourism industry has strong relevance with other industries. Authorities need to extend industry chain of forest tourism, and focus on the development of related industries. With the center of forest tourism market demand, the development of relevant industries, especially the third industry should be guided and promoted. Authorities also need to increase investment on tourism infrastructure and promote related construction to lay a good material foundation for forest tourism development. Thus, the added value of forest tourism products can be increased, and the overall efficiency of forest tourism industry can be improved. In this way, forest tourism industry can better promote the development of economy and the third industry.

Strengthening inter-regional cooperation. In 2015, the high-speed railway of $\mathrm{He}-\mathrm{Fu}$ brought new opportunities to Nanping region and surrounding areas. It also brings new opportunities for the development of forest tourism in these counties. Through the tourism cooperation with surrounding areas, tourism industry in Nanping develops rapidly, and brings about good economic effects. Multi-industry cooperation and cross regional cooperation play important roles in that process. In September 25, 2015, construction of Qu-Ning railway started. Stations of the railway include Songxi and Zhenghe, which will further promote the cooperation of tourism industry between these counties, and form connected effects.

\section{Acknowledgement}

Project Fund: This project is supported by Foundation for the Projects of Ministry of Education Humanities and Social Sciences (Project No.: 16YJA790068) and Foundation for the Soft Science Projects of Science and Technology Department of Fujian Province (Project No.: 2016R0037).

\section{References}

[1] Khan H, Seng C F, Cheong W. K. Tourism Multiplier Effects on Singapore[J]. Annals of Tourism Research, 1990, 17( 3) : 408- 418.

[2] Wanger J. Estimating the Economic Impacts of Tourism[J]. Annals of Tourism Research, 1997, 24(3): 592-608.

[3] West G, Gamage A. Macro Effects of Tourism in Victoria, Australia: A Nonlinear input-out Approach[J]. Journal of Travel Research, 2001, 40(1) : 101-109. 
[4] Brida J G, Carrera E, Risso W. A. Tourism's Impact on long-run Mexican Economic Growth[J]. Economics Bulletin, 2008, 3(7) : 1-10.

[5] Schubert S F, Brida J G, Risso W A. The Impacts of International Tourism Demand on Economic Growth of Small Economies Dependent on Tourism[J].Tourism Management, 2011, 32: 377-385.

[6] Duo-xun Ba \& Fang-wei Zhou. Empirical Relationship between Tourism Development and Economic Growth in Gansu Province [J]. Resource Development \& Market, 2014, 30(4) : 510-512.

[7] Lee C, Chang C. Tourism Development and Economic Growth: A Closer Look at Panels[J]. Tourism Management, 2008, 29(1): 180-192.

[8] Yan-ping Xiang. The Analysis on the Spatial Autocorrelation of the Tourism Development and Economic Growth Based on the Empirical Data of Wuling Mountain Areas [J], Economic Geography, 2012, 32 (8): 172-175.

[9] Andrew B P. Tourism and the economic development of Cornwall [J]. Annals of Tourism Research, 1997, 24(3): 721 -735.

[10] Oh C-O. The Contribution of Tourism Development to Economic Growth in the Korean Economy[J]. Tourism Management, 2005, 26: 39-44.

[11] Jian Ding \& Yan Huang. Study on the Relationship Between Forest Tourism Development and Economic Growth in Heilongjiang Province [J]. China's Prices, 2016 (3): 83-85. 